\title{
Personalidad y liderazgo
}

Personality and leadership

\section{María del P. Gómez-Ortiz ${ }^{a}$ Eduardo Vázquez-Domínguez ${ }^{a}$}

\begin{abstract}
:
Specialists have studied leaders from different approaches, there are mainly four theories that support the personality from the perspective of leadership. Considering personality as a set of traits and qualities that shape the way of being of one person and distinguish it from another.

On the one hand, it has the oldest theory based on personality traits, where it is claimed that the leaders were born with qualities and innate characteristics.

On the other hand, there is a theory based on behavioral styles developed in the 1950s, which refers to the leader being usually of three leadership styles: the Democrat, the autocrat and finally the Laissez faire.

The other theory is "administrative Grid" this being a graphical representation of supervision. This represents an interest in both for production and for employees.

Finally, we have the contingency theory, developed in the 90s and the situational theory established in the year 2000. Which state that personality traits are too simplistic and limited, since they ignore situational variables that cannot remain without importance.
\end{abstract}

\section{Keywords:}

Personality, leadership, leader, organization

\section{Resumen:}

Especialistas han estudiado a los líderes desde diferentes enfoques, existen principalmente cuatro teorías que sustentan la personalidad desde la perspectiva del liderazgo. Considerand o a la personalidad como un conjunto de rasgos y cualidades que configuran la manera de ser de una persona y la distinguen de otra.

Por un lado, se tiene la teoría más antigua basada en los rasgos de la personalidad, donde esta aseguraba que los líderes nacían con cualidades o características innatas.

Por otra parte, se tiene la teoría basada en los estilos del comportamiento, desarrollada en los años cincuenta, esta hace referencia a que el líder suele ser de tres estilos de liderazgo: el demócrata, el autócrata y por último el Laissez faire.

La otra teoría "Rejilla administrativa" siendo esta una representación gráfica de la supervisión. Se interpreta por el interés tanto en la producción como por la gente”.

Por último, se tienen la teoría de contingencia, desarrollada en los años 90 y la teoría situacional establecida en el año 2000. Las cuales manifiestan que los rasgos de la personalidad son demasiados simplistas y limitadas, ya que estas ignoran variables situacionales que no pueden quedar sin importancia.

\section{Palabras Clave:}

Personalidad, liderazgo, líder, organización

\footnotetext{
María del Pilar Gómez Ortiz, Universidad Autónoma del Estado de Hidalgo, https://orcid.org/0000-0001-6446-0901, Email: mgomezo@uaeh.edu.mx

a Eduardo Vázquez Domínguez, Universidad Autónoma del Estado de Hidalgo, https://orcid.org/0000-0001-9864-0898, Email: evd_2000@yahoo.com.mx
} 


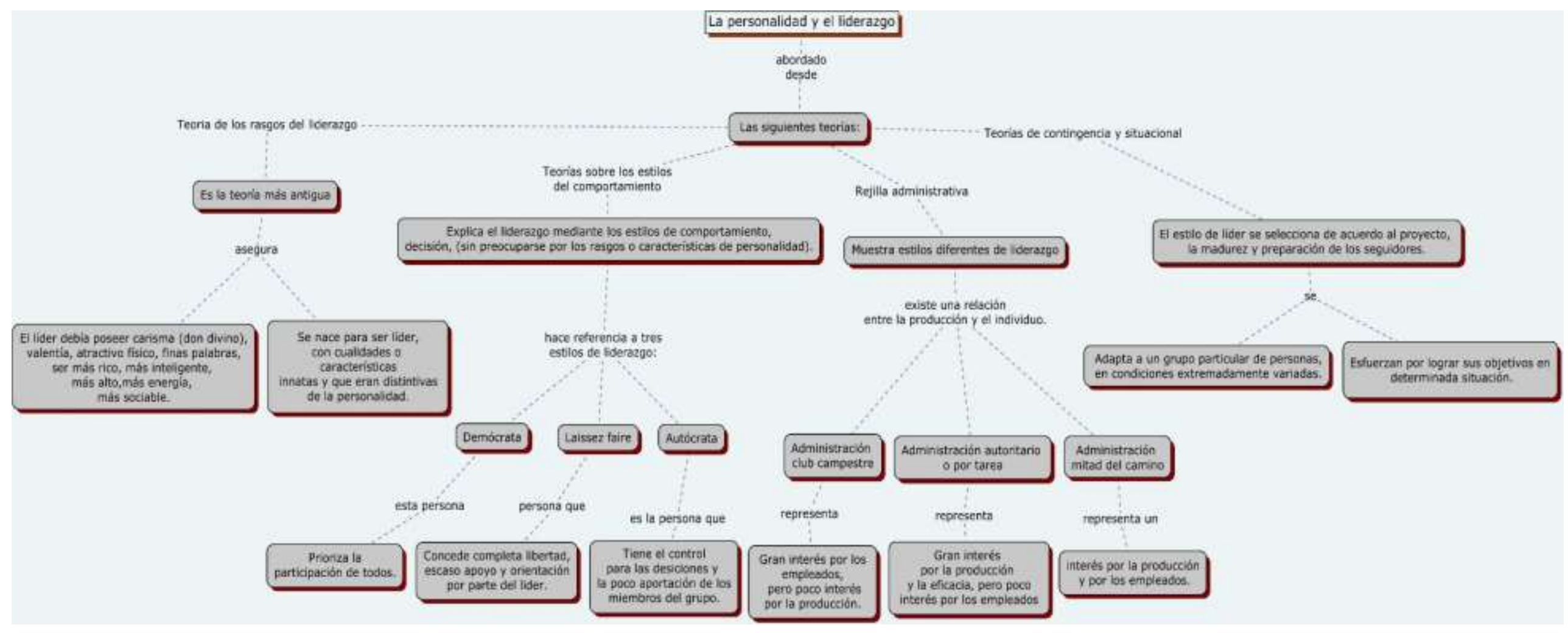




\section{Referencias}

Robbins, S.P. \& Judge, T. A. (2009). Comportamiento OrganizacionalDécimo tercera edición. México: Pearson Educación.

Kohler, P. (2017). Comunicación y liderazgo para jóvenes. 7ma edición. México: Éxodo.

Torres, B. (2013) Lideres y liderazgo. 1era edición. Guadalajara: Universidad centro universitario de Ciencias Económico Administrativo. 